Original Research Paper

\title{
Visual Curvatures of H1N1 Incidences in African, Asian, European, American and Oceanic Nations
}

\author{
Ramalingam Shanmugam \\ School of Health Administration, Texas State University, San Marcos, TX 78666, USA
}

Article history

Received: 11-07-2015

Revised: 4-8-2015

Accepted: $23-10-2015$

Email: shanmugam@txstate.edu

\begin{abstract}
The World Health Organization (WHO) was worried about the outbreak of H1N1 epidemic worldwide as it consumed several human lives. In a novel manner, this article defines, computes and illustrates the effectiveness of health administrators' efforts to extinguish pandemic H1N1 using curvature concept. Data on weekly incidences of H1N1 in year 2009 among the nations in Africa, Asia, Europe, Americas and Oceanic continents are utilized to compare continents and nations within the continent. A knowledge discovery from the data analysis of 2009 incidences is a necessity before any future incidences erupt. For stochastic reasons, which are stated and explained in the article, an Incidence Rate Restricted Inverse Binomial Distribution (IRRIBD) is introduced in this article to be an appropriate underlying model for the data. The plasticity of IRRIBD to explain the dynamics of the influenza is investigated. The actual H1N1 incidences during 2009 are analyzed and interpreted using IRRIBD in the illustration.
\end{abstract}

Keywords: Count/Discrete Probability Distributions, Incidence Rate Restricted Inverse Binomial

\section{Introduction}

The H1N1 is a swine Flu (as it expresses antigens $\mathrm{H}$ or N). This particular influenza is confirmed by a lab test and not by its symptoms: Fever, sore throat, nasal congestion, cough, respiratory problems, or body aches. The name "swine" was selected because people caught it first in direct contact with pigs. On June 11, 2009, WHO declared that H1N1 was the first global pandemic since the 1968 Hong Kong flu. See Saito et al. (2013; Jain et al., 2009; Smith et al., 2009; Vijaykrishna et al., 2010) for details on 2009 H1N1 pandemic.

The H1N1 virus is destroyed only by heat at highlevel temperature $167-212^{\circ} \mathrm{F}$ (equivalently, $75-100^{\circ} \mathrm{C}$ ). On October 25, 2009, the U.S. President Barack Obama officially declared that H1N1 was a national emergency. In May 2009, the Chinese government confined 21 U.S. students and 3 teachers to their hotel rooms. Australia ordered a cruise ship with 2,000 passengers to stay at sea because of a swine flu. Japan quarantined 47 airline passengers in a hotel for a week in mid-May 2009. In mid-June 2009, India ordered pre-screening the "outbound" passengers from the countries thought to have a high rate of infection.
Pregnant women have a higher risk to get H1N1 case. About 18,138 deaths occurred worldwide before the start of year 2010. Only on August 10, 2010, the WHO declared that the H1N1 pandemic was over. Hence, in a novel manner, this article defines, computes and illustrates the effectiveness of health administrators' efforts to extinguish the H1N1 pandemic using curvature concept. Data in the public domain database (see www.cdc.gov) on weekly incidences of H1N1 in the year 2009 among the nations in Africa, Asia, Europe, Americas and Oceanic continents are analyzed and interpreted. The results are utilized to compare the continents and nations within a continent. The data are grouped in terms continents Africa, Asia, Europe, Americas and Oceanic as in Tables 1 through 5 for the sake comparing the prevalence and spread of the influenza among as well as within the continents.

In a novel manner, a new probability model is introduced in this article to capture the effectiveness of health administrators' efforts to extinguish pandemic H1N1 and it is named Incidence Rate Restricted Inverse Binomial Distribution (IRRINBD). Using curvature concept and IRRIBD as the underlying 
model for the data, the weekly incidences of H1N1 in year 2009 among the nations in Africa, Asia, Europe, Americas and Oceanic continents are analyzed, interpreted and utilized to compare the continents and the nations within the continent. Boswell et al. (1990) for the importance of finding the most appropriate underlying model of the data in any data analysis. A knowledge discovery from such data analysis of 2009 incidences is a necessity before any future incidences erupt. Stochastic reasons are stated and explained in the article to consider an Incidence Rate Restricted Inverse Binomial Distribution (IRRIBD) to be an appropriate underlying model for the data in this article. The main concept and its tools to analyze data are presented in section 2 and they are illustrated in section 3 with the WHO's recorded incidences of H1N1 worldwide. The limitation of the new model is spelled out in the end.

\section{Curvature and 2009 Pandemic H1N1 Incidences}

Let $Y$ be the number of H1N1 weekly cases in a nation with an incidence rate $\lambda>0$. Because $\mathrm{H} 1 \mathrm{~N} 1$ is a new and rare type until a case is reported, the stochastic nature of its eruption is Poisson distribution:

$$
\begin{aligned}
& \operatorname{Pr}[Y=y \mid \lambda] \\
& =e^{-\lambda} \lambda^{y} / y ! ; \\
& \lambda>0 ; y=0,1,2, \ldots, \infty
\end{aligned}
$$

conditional on an unknown incidence rate. The incidence rates do stochastically vary among the nations due to their own environmental differences and people's hygienic habits. Let us assume that the stochastic nature of the $\mathrm{H} 1 \mathrm{~N} 1$ incidences is a continuous gamma distribution:

$$
\begin{aligned}
& f(\lambda \mid a, b) d \lambda=\left\{a^{y} e^{-a \lambda} \lambda^{b-1} / \Gamma(b)\right\} d \theta ; \\
& \lambda>0 ; a>0 ; b>0
\end{aligned}
$$

Unconditionally, the weekly number of H1N1 cases is then a re-parametrized Inverse Binomial Distribution (IBD):

$$
\begin{aligned}
& \operatorname{Pr}[Y=y \mid \theta, r] \\
& =\int_{0}^{\infty} \operatorname{Pr}[Y=y \mid \lambda] f(\lambda \mid a, b) d \lambda \\
& =\left(\begin{array}{c}
r+y-1 \\
y
\end{array}\right) \theta^{y}(1-\theta)^{r} ; \\
& y=0,1,2, \ldots, \infty ; \theta>0 ; r>0
\end{aligned}
$$

The parameter $r$ in IBD (2) is recognized as a heterogeneity level of the participating units in the data (Evans et al. (2000).

To begin with, let us consider a situation in which no incidence of H1N1 pandemic. According to IBD (2), the probability of no incidence of N1N1 is:

$\pi_{0}=\operatorname{Pr}[Y=0 \mid \theta, r]=(1-\theta)^{r}$

where, $\theta$ and $r$ are the incidence and a heterogeneity parameter respectively. Let us invert (3a) to learn that the incidence rate is a function of (that means controlled by) the chance for no H1N1 incidence. That is, $\theta=1-\pi_{0}^{1 / r}$. When $\pi_{0}$ increases, the rate $\theta$ decreases:

$\pi_{1}=\operatorname{Pr}\left[Y=1 \mid \theta=\pi_{0}^{-1}, r\right]$
$=r \pi_{0}\left(1-\pi_{0}^{1 / r}\right)$

The probability of "one HIN1 incidence" also depends on $\pi_{0}$ of "no H1N1 incidence". Their relationship is nonlinear. Nonlinear means an existence of curvature (which will be discussed later in the article), which ought to hold additional details. To visualize it, see its sketch in Fig. 1, where $\pi_{1}, \pi_{0}$ and $r$ are indicated in $\mathrm{y}, \mathrm{x}$ and $\mathrm{z}$ - axis respectively. A characteristic property of IBD (2) is that the mean:

$\mu=r\left(\pi_{0}^{-1 / r}-1\right)$

is smaller than its variance:

$\sigma^{2}=\frac{\mu}{\pi_{0}^{1 / r}}$

An estimate of the heterogeneity level, $r$ is then:

$\hat{r}=\left|\frac{\ln \hat{\pi}_{0}}{\ln \left(\frac{\bar{y}}{s_{y}^{2}}\right)}\right|$

The H1N1 incidences of the year 2009 are displayed in the Table 1 through Table 5. The plot of data variance $s_{y}^{2}$ in terms of the data mean $\bar{y}$ is done for each continent in Fig. 2 through Fig. 6 indicate. The variance increases as the mean increases up to a point, then decreases as the mean increases. The variance is, therefore, in a parabolic relation with the mean. For the NBD (2) to be the underlying model for the H1N1 data, the variance should be monotonically increasing with the mean. It did not happen so. The plots indicate that the characteristic of IBD (2) is validated in some nations but not in all nations in the five continents. Using the IBD (2) for full data analysis is not appropriate. A new model for the data is necessary. 


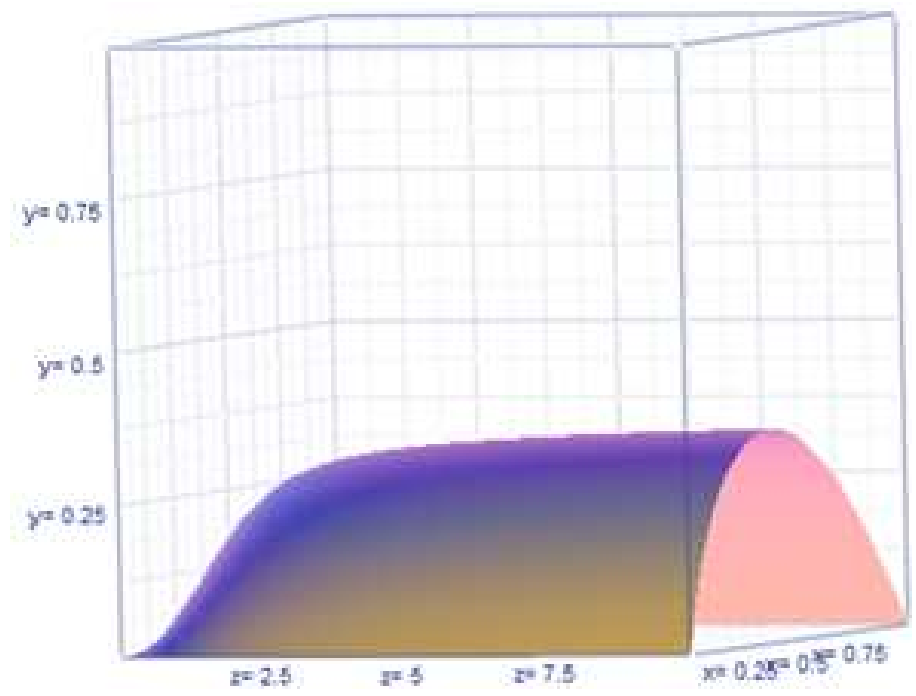

Fig. 1. Nonlinear and curvature relation among $\pi_{1}, \pi_{2}$ and $r$

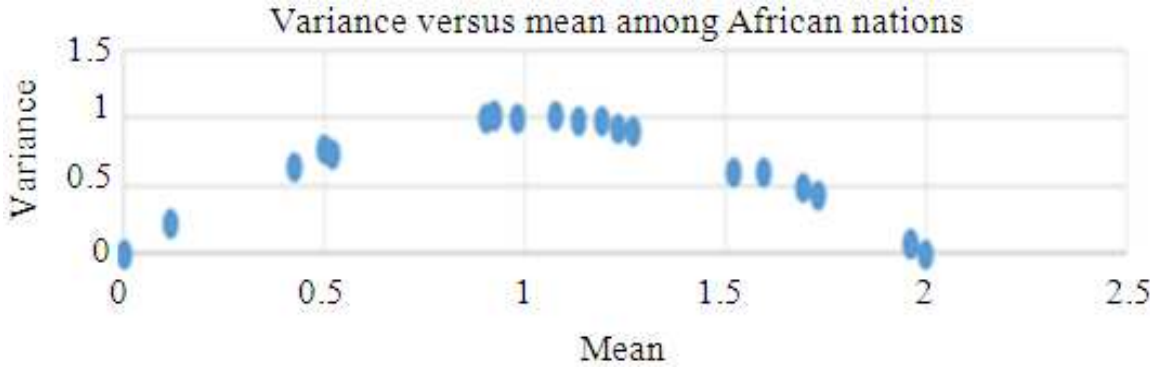

Fig. 2. Variance versus mean in African nations

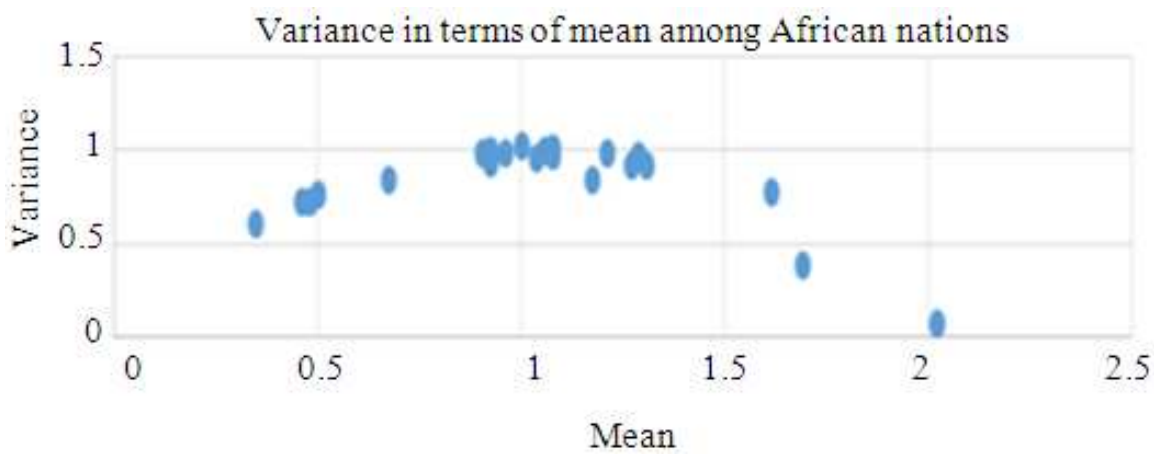

Fig. 3. Variance versus mean in Asian nations

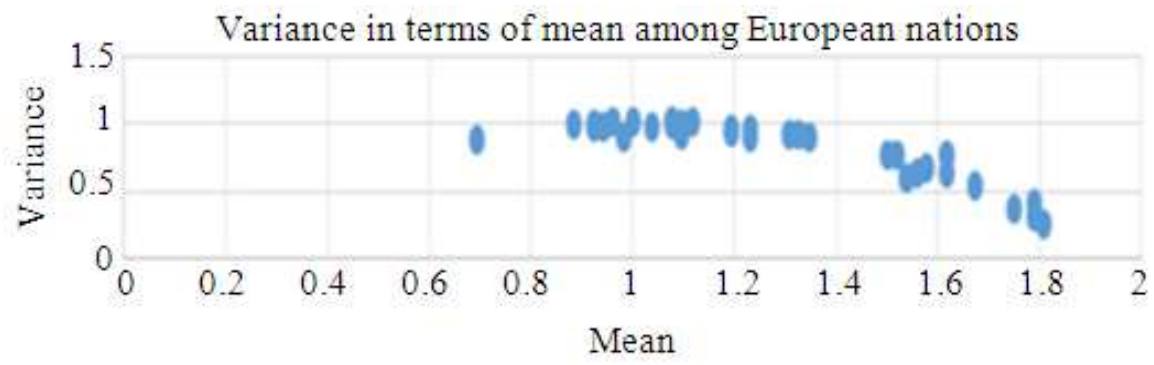

Fig. 4. Variance versus mean in European nations 


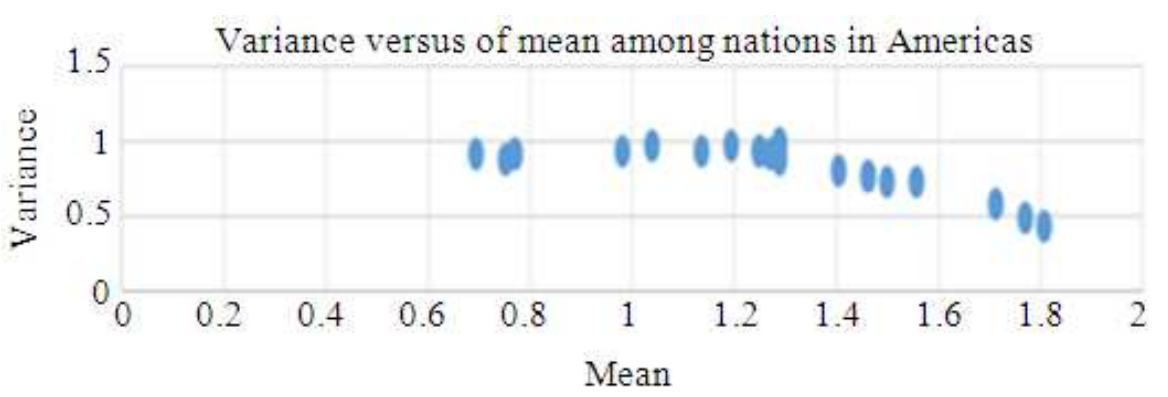

Fig. 5. Variance versus mean in American nations

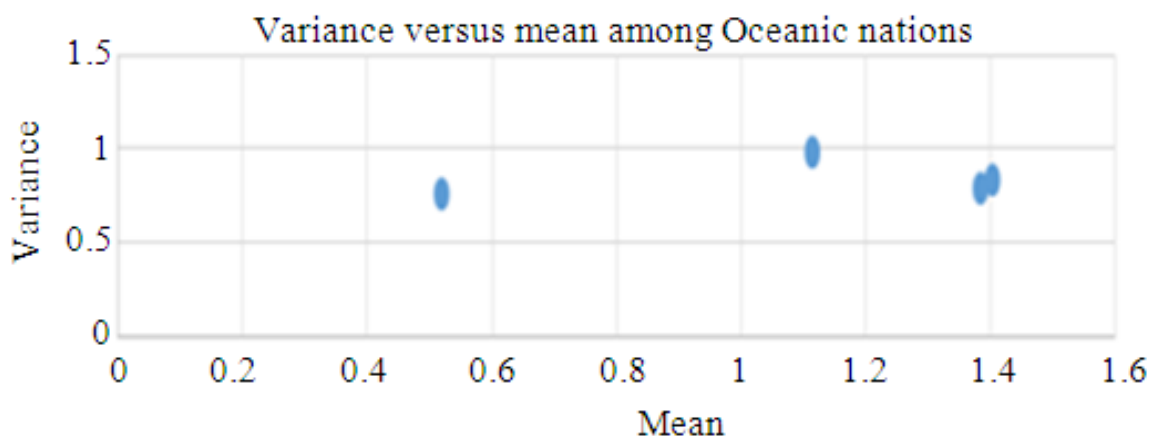

Fig. 6. Variance versus mean in Oceanic nations

A dilution/escalation of the model characteristic occurs due to sudden pandemic volatility of H1N1 due to the effectiveness of health administrators' efforts to extinguish pandemic H1N1. Let $\phi$ refer the effectiveness of health administrators' efforts to extinguish pandemic H1N1. Then, the IBD is generalizable to:

$$
\begin{aligned}
& \operatorname{Pr}[Y=y \mid \theta, r, \phi] \\
& =\frac{r}{\left(r+\frac{y}{\phi}\right)}\left(r+\frac{y}{\phi}\right) \theta^{y}(1-\theta)^{r+\left(\frac{1}{\phi}-1\right) y} ; \\
& y=0,1,2, \ldots, \infty ; r>0 ; 0<\theta<\phi<1,
\end{aligned}
$$

which is named in this article as the Incidence Rate Restricted Inverse Binomial Distribution (IRRIBD). The mean and variance of IRRIBD (6) are respectively:

$$
\mu=\frac{r\left(1-\pi_{0}^{1 / r}\right)}{\left(1-\frac{\left[1-\pi_{0}^{1 / r}\right]}{\phi}\right)}
$$

and

$$
\sigma^{2}=\frac{\mu \pi_{0}^{1 / r}}{\left(1-\frac{\left[1-\pi_{0}^{1 / r}\right]}{\phi}\right)^{2}}
$$

Let us examine the situation in which not a perfect effectiveness of health administrators' efforts to extinguish pandemic H1N1 (that is, $\phi \neq 1$ ). The probability of no H1N1 incidence is $\pi_{0}=\operatorname{Pr}[Y=0 \mid \theta, r, \phi]$ $=(1-\theta)^{r}$, which is, obviously and understandably independent of the effectiveness, $\phi$ of health administrators' efforts to extinguish the pandemic H1N1. That is, $\theta=1-\pi_{0}^{1 / r}$. When $\pi_{0}$ increases, the incidence rate $\theta$ decreases as one would expect:

$$
\begin{aligned}
& \pi_{1}=\operatorname{Pr}[Y=1 \mid \theta, r, \phi] \\
& =r\left(1-\pi_{0}^{1 / r}\right) \pi_{0}^{1+\left(\frac{1}{\phi}-1\right) / r}
\end{aligned}
$$

The probability of "one H1N1 incidence" depends on the effectiveness, $\phi$ of health administrators' efforts to extinguish the pandemic H1N1. When the effectiveness, $\phi o f$ health administrators' efforts to extinguish the pandemic H1N1 is at the full capacity baseline value (that is, $\phi=1$ ), the probability mass function of IRRIBD (6), its mean (7) and variance (8) reduce to their counterparts of the IBD (2), its mean (4) and variance (5) respectively. The relationship (9) reduces to the relationship (3) as a particular case under the baseline value, $\phi=1$.

How do these translate to the medical researchers or epidemiologists? Using the IBD (2) as an underlying model for the $2009 \mathrm{H} 1 \mathrm{~N} 1$ data makes a preponderant assumption that the effectiveness, $\phi$ of health administrators' efforts to extinguish the pandemic H1N1 
is at the full capacity baseline value (that is, $\phi=1$ ). It may not be the reality for several reasons. The IRRIBD (6) is a model for the underlying data. What is model? A model is supposed to be an abstraction of the reality. In this framework, the model (6) is versatile enough to capture the actual reality of the pandemic volatility of H1N1 and the effectiveness, $\phi$ of health administrators' efforts to extinguish the pandemic H1N1.

A picture is worth the thousands to comprehend, especially when the reality is complex and volatile. The mean and variance of both the IBD (2) and IRRIBD (6) possess a nonlinearity. Nonlinearity means the existence of curvature. What is really the curvature concept? The curvature of a nonlinear curve at a point is a measure of how sensitive its tangent line is to moving the point to other nearby points. A straight line has zero curvature. Large circles should have smaller curvature than small circles, which bend more sharply. The absolute value of the curvature is a measure of how sharply the curve bends. Curves, which swing to the left, have positive curvature and curves, which swing to the right, have negative curvature. For a real-life meaning of curvature, why not listen to the geologists. They assert that the earth curves approximately 6 feet in 9 miles. In which case, what would the distance between two boats of 6 feet height who could not see each other in an ocean because of the curvature of the earth? The two boats would have to be approximately 18 miles apart Sokolov (2001; Cloud, 2000; James, 1996) for applications of the curvature.

The visuals in Fig. 7 and Fig. 8 confirm the existence of curvature in the relationship of the mean (7) and variance (8) for example, when $r=1$. The Fig. 7 and Fig. 8 are sketched with $\mu, \pi_{0}$ and $\phi$ in $y, x$ and $\mathrm{z}-$ axis respectively. The curvature of the mean (4) of IBD with the baseline value $\phi=1$ is the sliding but unbent plate in Fig. 7. The curvature of the mean (7) of the IRRIBD with a versatile effectiveness, $\phi$ of health administrators' efforts to extinguish the pandemic H1N1 (that is, $\phi \neq 1$ ) is the twisted and bent plate in Fig. 7. The curvature of the variance (5) of IBD with the baseline value $\phi=1$ is the sliding but unbent plate in Fig. 8. The curvature of the mean (8) of the IRRIBD with a versatile pandemic volatility $\phi \neq 1$ of H1N1 is the two-sided, twisted and bent plate in Fig. 8 .

The curvature can also be quantified numerically. In this framework, the "curvature" of a bent/twisted plate is defined by a quantitative measure:

$$
\kappa_{0}=\frac{\left|\partial_{\pi_{0}}^{2} \pi_{1}\right|}{\left(1+\left[\partial_{\pi_{0}}^{1} \pi_{1}\right]^{2}\right)^{3 / 2}},
$$

which captures how the probability of "one H1N1 incidence" shifts because of the probability of "no H1N1 incidence", where $\partial_{\pi_{0}}^{1}$ and $\partial_{\pi_{0}}^{2}$ denote the first and second derivative with respect to $\pi_{0}$.

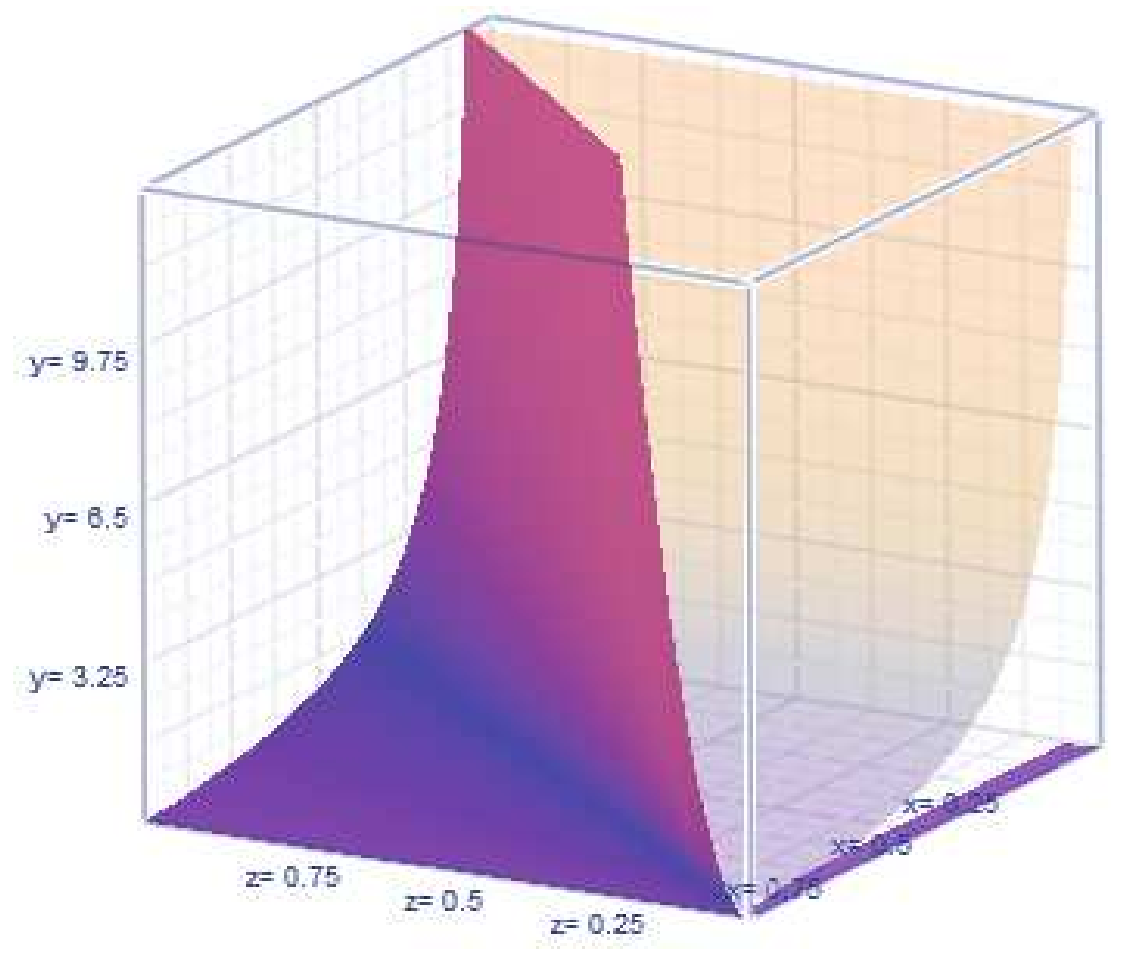

Fig. 7. Mean (5) with $\phi \neq 1$ and $\phi=1$ 


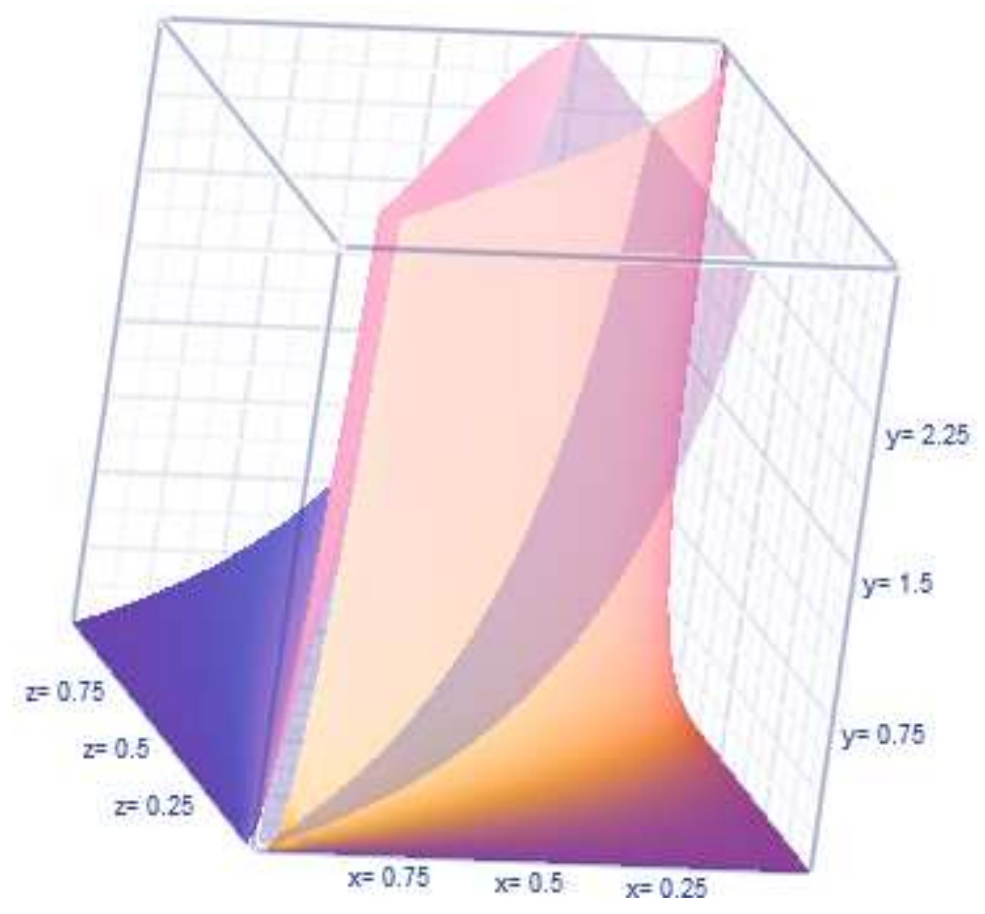

Fig. 8. Variance (6) with $\phi \neq 1$ and $\phi=1$

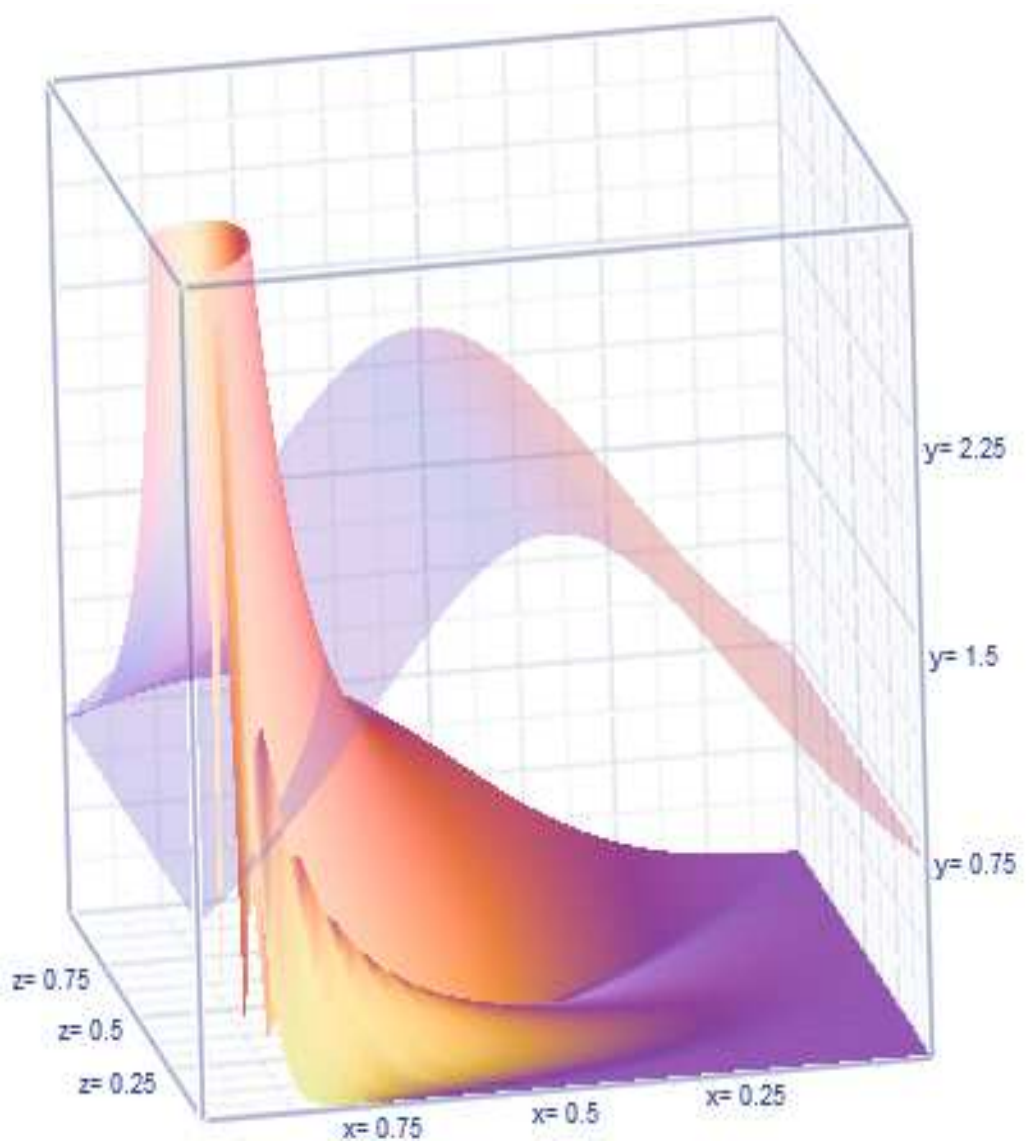

Fig. 9. Curvatures (11a) with volatility, $\phi \neq 1$ and (11b) at baseline, $\phi=1$ 
The quantity $K_{0}$ is recognized in physics and engineering as the equation of bending in beams, the vibration of a tense string, the fluid flow around surfaces in aeronautics, and the surface boundary conditions in ocean waves:

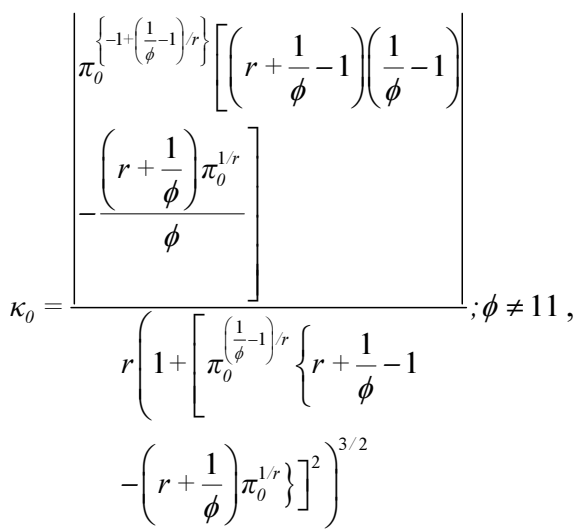

or

$\kappa_{0}=\frac{\left.\mid(r+1) \pi_{0}^{(1 / r)-1}\right] \mid}{r\left(1+\left[r\left(1-\pi_{0}^{1 / r}\right)-\pi_{0}^{1 / r}\right]^{2}\right)^{3 / 2}} ; \phi=1$
The curvature for the IRRNBD (6) based on (9) is, after simplifications, that depending on whether the effectiveness, $\phi$ of health administrators' efforts to extinguish the pandemic $\mathrm{H} 1 \mathrm{~N} 1$ is at a real level or at the baseline (that is, perfect) level. For an example, when $r=1$, the curvatures (11a) and (11b) appear like in the Fig. 9, where $K_{0}, \pi_{0}$ and $\phi$ are indicated in $\mathrm{y}, \mathrm{x}$ and $\mathrm{z}$ - axis respectively.

\section{Illustration of Health Administrators' Effectiveness to Extinguish 2009 H1N1}

In this section, the derived curvature expressions of the section 2 are computed, interpreted and compared with the $2009 \mathrm{H} 1 \mathrm{~N} 1$ incidences in the nations of five continents: Africa, Asia, Europe, Americas and Oceania. The number, $\mathrm{Y}$ of $\mathrm{H} 1 \mathrm{~N} 1$ incidences are displayed in Tables 1 through 5.

A characteristic property of the NBD (2) is that the variance $s_{y}^{2}$ is larger than the mean, $\bar{y}$ This property is not validated (see Tables 1 through 5) in all nations of the five continents. The NBD (2) is not the underlying model for the $2009 \mathrm{H} 1 \mathrm{~N} 1$ incidence data. There is a need to look for an appropriate underlying model, which captures the actually attained effectiveness, $\phi$ of health administrators' efforts to extinguish the pandemic H1N1. Such an appropriate model is the IRRNBD (6).

Table 1. Weekly incidences of H1N1 during 2009 in African nations (* NA arises because of no frequency of zero or one H1N1 incidence)

\begin{tabular}{|c|c|c|c|c|c|c|c|c|}
\hline Nation & $\begin{array}{l}\text { \# weeks with } \\
\text { no incidence }\end{array}$ & $\begin{array}{l}\text { \# weeks with } \\
\text { one incidence }\end{array}$ & $\begin{array}{l}\text { \# weeks with } \\
\text { multiple incidences }\end{array}$ & Mean, $\bar{y}$ & Variance, $s_{y}^{2}$ & Is $s_{y}^{2}>\bar{y} ?$ & $\hat{\phi}$ & $\hat{r}$ \\
\hline Algeria & 6.0 & 2.0 & 44.0 & 1.73 & 0.44 & No & 0.40 & 1.57 \\
\hline Cameroon & 39.0 & $0^{*}$ & 13.0 & 0.50 & 0.76 & Yes & NA & 0.68 \\
\hline Cape Verde & 9.0 & 7.0 & 36.0 & 1.52 & 0.61 & No & 0.43 & 1.91 \\
\hline Côte d'Ivoire & 37.0 & 3.0 & 12.0 & 0.52 & 0.73 & Yes & 0.21 & 1.02 \\
\hline Egypt & 22.0 & 1.0 & 29.0 & 1.13 & 0.98 & No & 0.04 & 5.93 \\
\hline Gambia & 10.0 & $0^{*}$ & 51.0 & 1.96 & 0.08 & No & NA & 1.22 \\
\hline Ghana & 400.0 & 2.0 & 10.0 & 0.42 & 0.64 & Yes & 0.24 & 0.63 \\
\hline Guinea & 28.0 & $0^{*}$ & 24.0 & 0.92 & 1.01 & Yes & NA & 6.62 \\
\hline Guinea-Bissau & 1.0 & $0^{*}$ & 51.0 & 1.96 & 0.08 & No & NA & 1.22 \\
\hline Kenya & 26.0 & 1.0 & 25.0 & 0.98 & 1.00 & Yes & 0.01 & 36.4 \\
\hline Madagascar & 28.0 & 0( & 24.0 & 0.92 & 1.01 & Yes & NA & 6.62 \\
\hline Martinique & 28.0 & 1.0 & 23.0 & 0.90 & 0.99 & Yes & 0.03 & 6.76 \\
\hline Mauritania & 49.0 & $0^{*}$ & 3.0 & 0.12 & 0.22 & Yes & NA & 0.09 \\
\hline Morocco & 19.0 & 2.0 & 31.0 & 1.23 & 0.93 & No & 0.09 & 3.54 \\
\hline Senegal & 52.0 & $0^{*}$ & $0^{*}$ & 0.00 & 0.00 & NA & NA & NA \\
\hline Sierra Leone & 21.0 & $0^{*}$ & 31.0 & 1.19 & 0.98 & No & NA & 4.67 \\
\hline South Africa & 24.0 & $0^{*}$ & 28.0 & 1.08 & 1.01 & No & NA & 12.8 \\
\hline Sudan & 9.0 & 3.0 & 40.0 & 1.60 & 0.60 & No & 0.33 & 1.79 \\
\hline Tanzania & 0.0 & $0^{*}$ & 52.0 & 2.00 & 0.00 & No & NA & NA \\
\hline Tunisia & 18.0 & 2.0 & 32.0 & 1.27 & 0.91 & No & 0.11 & 3.15 \\
\hline Uganda & 7.0 & 2.0 & 43.0 & 1.69 & 0.49 & No & 0.36 & 1.62 \\
\hline Mean & 8.5 & 1.8 & 41.8 & 1.64 & 0.50 & & 0.27 & 2.19 \\
\hline Var & 55.0 & 1.6 & 68.3 & 0.09 & 0.14 & & 0.02 & 0.7 .0 \\
\hline
\end{tabular}


Ramalingam Shanmugam / Current Research in Medicine 2015, 6 (2): 14.26 DOI: $10.3844 /$ amjsp.2015.14.26

Table 2. Weekly incidences of H1N1 during 2009 in Asian nations (* NA arises because of no frequency of zero or one H1N1 incidence)

\begin{tabular}{|c|c|c|c|c|c|c|c|c|}
\hline Nation & $\begin{array}{l}\text { \# weeks with } \\
\text { no incidence }\end{array}$ & $\begin{array}{l}\text { \# weeks with } \\
\text { One incidence }\end{array}$ & $\begin{array}{l}\text { \# weeks with } \\
\text { multiple incidences }\end{array}$ & Mean, $\bar{y}$ & Variance, $s_{y}^{2}$ & Is $s_{y}^{2}>\bar{y}$ ? & $\hat{\phi}$ & $\hat{r}$ \\
\hline Afghanistan & 5.0 & 3.0 & 44.0 & 1.69 & 0.391 & no & 0.5 & 1.60 \\
\hline Cambodia & 1.0 & $0 *$ & 51.0 & 2.02 & 0.080 & no & NA & 1.23 \\
\hline China & 18.0 & 1.0 & 33.0 & 1.27 & 0.916 & no & 0.1 & 3.25 \\
\hline Georgia & 160.0 & 6.0 & 30.0 & 1.17 & 0.837 & no & 0.2 & 3.50 \\
\hline India & 13.0 & $0 *$ & 39.0 & 1.62 & 0.778 & no & NA & 1.90 \\
\hline Iran & 27.0 & 1.0 & 24.0 & 0.92 & 0.997 & Yes & 0.0 & 8.51 \\
\hline Iraq & 37.0 & 3.0 & 12.0 & 0.48 & 0.727 & Yes & 0.3 & 0.82 \\
\hline Israel & 20.0 & $0 *$ & 32.0 & 1.29 & 0.969 & no & NA & 3.35 \\
\hline Japan & 18.0 & $0 *$ & 34.0 & 1.31 & 0.923 & no & NA & 3.05 \\
\hline Kazakhstan & 26.0 & $0 *$ & 26.0 & 1.00 & 1.020 & Yes & NA & 35.70 \\
\hline Korea & 24.0 & $0 *$ & 28.0 & 1.08 & 1.014 & no & NA & 12.80 \\
\hline Kyrgyzstan & 23.0 & 5.0 & 24.0 & 0.92 & 0.931 & Yes & 0.0 & 100.00 \\
\hline Malaysia & 370.0 & $0 *$ & 15.0 & 0.67 & 0.847 & Yes & NA & 1.48 \\
\hline Mongolia & 40.0 & $0 *$ & 12.0 & 0.46 & 0.724 & Yes & NA & 0.58 \\
\hline Oman & 39.0 & $0 *$ & 13.0 & 0.50 & 0.765 & Yes & NA & 0.68 \\
\hline Pakistan & 39.0 & 4.0 & 9.0 & 0.35 & 0.608 & Yes & 0.5 & 0.51 \\
\hline Philippines & 24.0 & 3.0 & 25.0 & 1.04 & 0.961 & no & 0.0 & 9.95 \\
\hline Singapore & 29.0 & 1.0 & 22.0 & 0.90 & 0.983 & Yes & 0.0 & 6.95 \\
\hline Sri Lanka & 24.0 & 1.0 & 27.0 & 1.06 & 0.997 & no & 0.0 & 13.00 \\
\hline Thailand & 21.0 & $0 *$ & 31.0 & 1.21 & 0.982 & no & NA & 4.32 \\
\hline Turkey & 22.0 & 2.0 & 28.0 & 1.08 & 0.968 & no & 0.0 & 8.09 \\
\hline Viet Nam & 26.0 & 2.0 & 24.0 & 0.96 & 0.979 & Yes & 0.0 & 38.80 \\
\hline Mean & 23.0 & 1.3 & 28.0 & 1.08 & 0.980 & & 0.0 & 16.00 \\
\hline Var & 4.9 & 0.9 & 8.3 & 0.01 & 0.000 & & 0.0 & 242.00 \\
\hline
\end{tabular}

Table 3. Weekly incidences of H1N1 during 2009 in European nations (*NA arises because of no frequency of zero or one H1N1 incidence)

\begin{tabular}{|c|c|c|c|c|c|c|c|c|}
\hline Nation & $\begin{array}{l}\# \text { weeks with } \\
\text { no incidence }\end{array}$ & $\begin{array}{l}\# \text { weeks with } \\
\text { One incidence }\end{array}$ & $\begin{array}{l}\text { \# weeks with } \\
\text { multiple incidences }\end{array}$ & Mean, $\bar{y}$ & Variance, $s_{y}^{2}$ & Is $s_{y}^{2}>\bar{y}$ ? & $\hat{\phi}$ & $\hat{r}$ \\
\hline Belarus & 11.00 & $0^{*}$ & 41 & 1.58 & 0.680 & No & NA & 1.85 \\
\hline Belgium & 24.00 & $0 *$ & 28 & 1.08 & 1.014 & No & NA & 12.80 \\
\hline Bulgaria & 9.00 & 3.0 & 40 & 1.54 & 0.602 & No & 0.31 & 1.87 \\
\hline Croatia & 24.00 & 1.0 & 27 & 1.10 & 0.998 & No & 0.03 & 8.25 \\
\hline Czech & 10.00 & 2.0 & 40 & 1.56 & 0.641 & No & 0.27 & 1.86 \\
\hline Denmark & 20.00 & 2.0 & 30 & 1.19 & 0.943 & No & 0.08 & 4.07 \\
\hline Estonia & 27.00 & 2.0 & 23 & 0.92 & 0.974 & Yes & 0.02 & 12.10 \\
\hline Finland & 34.00 & 1.0 & 17 & 0.69 & 0.891 & Yes & 0.09 & 1.68 \\
\hline France & 18.00 & $0^{*}$ & 34 & 1.33 & 0.923 & No & NA & 2.93 \\
\hline Germany & 17.00 & $0 *$ & 35 & 1.35 & 0.897 & No & NA & 2.76 \\
\hline Greece & 23.00 & 1.0 & 28 & 1.08 & 0.991 & No & 0.02 & 9.80 \\
\hline Hungary & 8.00 & 1.0 & 43 & 1.67 & 0.538 & No & 0.28 & 1.65 \\
\hline Ireland & 6.00 & $0 *$ & 46 & 1.79 & 0.417 & No & NA & 1.48 \\
\hline Italy & 18.00 & $0 *$ & 34 & 1.31 & 0.923 & No & NA & 3.05 \\
\hline Latvia & 28.00 & 1.0 & 23 & 0.88 & 0.991 & Yes & 0.03 & 5.45 \\
\hline Lithuania & 4.00 & 2.0 & 46 & 1.79 & 0.316 & No & 0.50 & 1.48 \\
\hline Luxembourg & 13.00 & 1.0 & 38 & 1.50 & 0.765 & No & 0.17 & 2.06 \\
\hline Macedonia & 5.00 & 2.0 & 45 & 1.75 & 0.377 & No & 0.45 & 1.53 \\
\hline Malta & 27.00 & $0 *$ & 25 & 1.00 & 1.020 & Yes & NA & 33.80 \\
\hline Moldova & 3.00 & 2.0 & 47 & 1.81 & 0.252 & No & 0.57 & 1.45 \\
\hline Netherlands & 18.00 & 3.0 & 31 & 1.23 & 0.897 & No & 0.11 & 3.36 \\
\hline Norway & 13.00 & 1.0 & 38 & 1.52 & 0.766 & No & 0.17 & 2.02 \\
\hline Poland & 21.00 & 6.0 & 25 & 0.98 & 0.905 & No & 0.04 & 11.30 \\
\hline Portugal & 13.00 & $0 *$ & 39 & 1.62 & 0.778 & No & NA & 1.90 \\
\hline Romania & 24.00 & $0 *$ & 28 & 1.08 & 1.014 & No & NA & 12.80 \\
\hline Russia & 27.00 & 1.0 & 24 & 0.92 & 0.997 & Yes & NA & 8.51 \\
\hline Serbia & 20.00 & 4.0 & 28 & 1.10 & 0.920 & No & 0.07 & 5.47 \\
\hline Slovakia & 10.00 & 2.0 & 40 & 1.62 & 0.643 & No & 0.28 & 1.79 \\
\hline Slovenia & 24.00 & 2.0 & 26 & 1.04 & 0.979 & No & 0.02 & 13.10 \\
\hline Spain & 28.00 & $0^{*}$ & 24 & 0.96 & 1.015 & Yes & NA & 11.40 \\
\hline Sweden & 23.00 & $0 *$ & 29 & 1.12 & 1.006 & No & NA & 7.91 \\
\hline Switzerland & 20.00 & 1.0 & 31 & 1.19 & 0.955 & No & 0.06 & 4.30 \\
\hline Ukraine & 26.00 & 2.0 & 24 & 0.94 & 0.979 & Yes & 0.01 & 18.00 \\
\hline UK & 20.00 & 1.0 & 31 & 1.23 & 0.955 & No & 0.07 & 3.76 \\
\hline Mean & 22.30 & 1.0 & 29 & 1.12 & 0.970 & & 0.05 & 8.50 \\
\hline Var & 8.25 & 0.7 & 11 & 0.02 & 0.000 & & 0.00 & 43.70 \\
\hline
\end{tabular}


Ramalingam Shanmugam / Current Research in Medicine 2015, 6 (2): 14.26 DOI: $10.3844 / \mathrm{amjsp} .2015 .14 .26$

\begin{tabular}{|c|c|c|c|c|c|c|c|c|}
\hline Nation & $\begin{array}{l}\text { \# weeks with } \\
\text { no incidence }\end{array}$ & $\begin{array}{l}\# \text { weeks with } \\
\text { One incidence }\end{array}$ & $\begin{array}{l}\text { \# weeks with } \\
\text { multiple incidences }\end{array}$ & Mean, $\bar{y}$ & Variance, $s_{y}^{2}$ & Is $s_{y}^{2}>\bar{y} ?$ & $\hat{\phi}$ & $\hat{r}$ \\
\hline Argentina & 18 & 1.0 & 33 & 1.27 & 0.916 & No & 0.10 & 3.25 \\
\hline Brazil & 19 & 1.0 & 32 & 1.25 & 0.936 & No & 0.10 & 3.48 \\
\hline Canada & 19 & $0 *$ & 33 & 1.29 & 0.946 & No & NA & 3.26 \\
\hline Chile & 23 & 2.0 & 27 & 1.04 & 0.976 & No & 0.00 & 13.1 \\
\hline Colombia & 13 & 2.0 & 37 & 1.46 & 0.763 & No & 0.20 & 2.13 \\
\hline Costa Rica & 21 & 1.0 & 30 & 1.19 & 0.970 & No & 0.10 & 4.39 \\
\hline Cuba & 20 & 3.0 & 29 & 1.13 & 0.932 & No & 0.10 & 4.85 \\
\hline Dominican & 9 & $0^{*}$ & 43 & 1.71 & 0.587 & No & NA & 1.64 \\
\hline Ecuador & 12 & 1.0 & 39 & 1.50 & 0.725 & No & 0.20 & 2.02 \\
\hline El Salvador & 17 & 2.0 & 33 & 1.29 & 0.884 & No & 0.10 & 2.97 \\
\hline French Guiana & 30 & 3.0 & 19 & 0.77 & 0.916 & Yes & 0.10 & 3.16 \\
\hline Guadeloupe & 30 & 4.0 & 18 & 0.75 & 0.887 & Yes & 0.10 & 3.27 \\
\hline Guatemala & 7 & 1.0 & 44 & 1.77 & 0.487 & No & 0.30 & 1.55 \\
\hline Honduras & 19 & 1.0 & 32 & 1.25 & 0.936 & No & 0.10 & 3.48 \\
\hline Jamaica & 23 & 4.0 & 25 & 0.98 & 0.943 & No & 0.00 & 20.8 \\
\hline Mexico & 6 & 1.0 & 45 & 1.81 & 0.430 & No & 0.40 & 1.50 \\
\hline Panama & 12 & $0 *$ & 40 & 1.56 & 0.724 & No & NA & 1.92 \\
\hline Paraguay & 27 & 5.0 & 20 & 0.77 & 0.913 & Yes & 0.10 & 3.84 \\
\hline Peru & 21 & $0^{*}$ & 31 & 1.29 & 0.991 & No & NA & 3.46 \\
\hline Suriname & 34 & $0 *$ & 18 & 0.69 & 0.923 & Yes & NA & 1.48 \\
\hline Uruguay & 13 & 1.0 & 38 & 1.46 & 0.765 & No & 0.20 & 2.14 \\
\hline USA & 14 & 2.0 & 36 & 1.40 & 0.798 & No & 0.20 & 2.32 \\
\hline Mean & 21 & 0.8 & 31 & 1.21 & 0.870 & & 0.17 & 2.35 \\
\hline Var & 94 & 0.9 & 81 & 0.12 & 0.010 & & 0.00 & 0.68 \\
\hline
\end{tabular}

Table 5. Weekly incidences of H1N1 during 2009 in Oceanic nation $(*$ NA arises because of no frequency of zero or one H1N1 incidence)

\begin{tabular}{|c|c|c|c|c|c|c|c|c|}
\hline Nation & $\begin{array}{l}\text { \# weeks with } \\
\text { no incidence }\end{array}$ & $\begin{array}{l}\text { \# weeks with } \\
\text { One incidence }\end{array}$ & $\begin{array}{l}\# \text { weeks with } \\
\text { multiple incidences }\end{array}$ & Mean, $\bar{y}$ & Variance, $s_{y}^{2}$ & Is $s_{y}^{2}>\bar{y} ?$ & $\hat{\phi}$ & $\hat{r}$ \\
\hline Australia & 22 & 1 & 29 & 1.12 & 0.982 & No & 0.03 & 6.75 \\
\hline Fiji & 36 & 3 & 13 & 0.52 & 0.763 & Yes & 0.23 & 0.96 \\
\hline New Caledonia & 15 & 2 & 35 & 1.4 & 0.83 & No & 0.16 & 2.37 \\
\hline New Zealand & 14 & 3 & 35 & 1.38 & 0.795 & No & 0.19 & 2.36 \\
\hline Mean & 22 & 2.3 & 28 & 1.11 & 0.842 & & 0.16 & 3.11 \\
\hline Var & 103 & 0.9 & 108 & 0.17 & 0.009 & & 0.01 & 6.33 \\
\hline
\end{tabular}

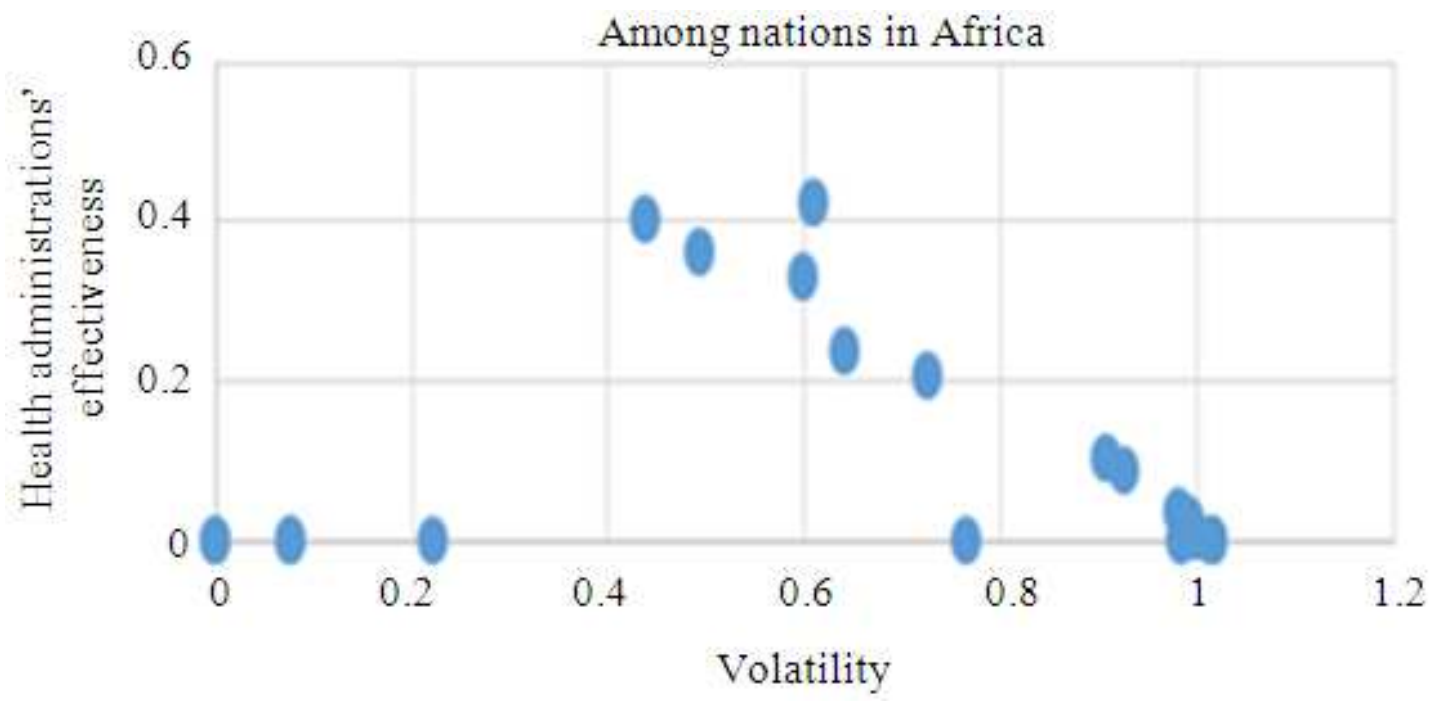

Fig. 10. Health administrators' effectiveness to extinguish H1N1 in Africa 


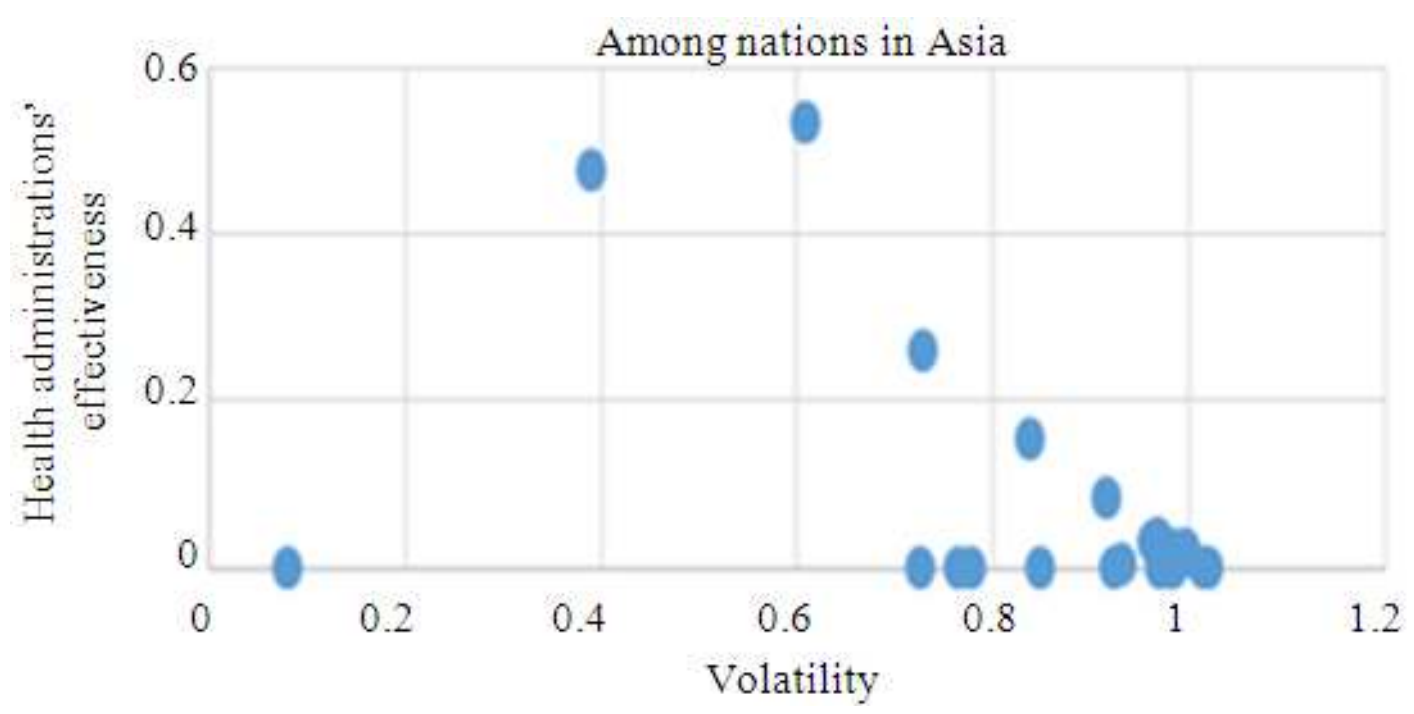

Fig. 11. Health administrators' effectiveness to extinguish H1N1 in Asia

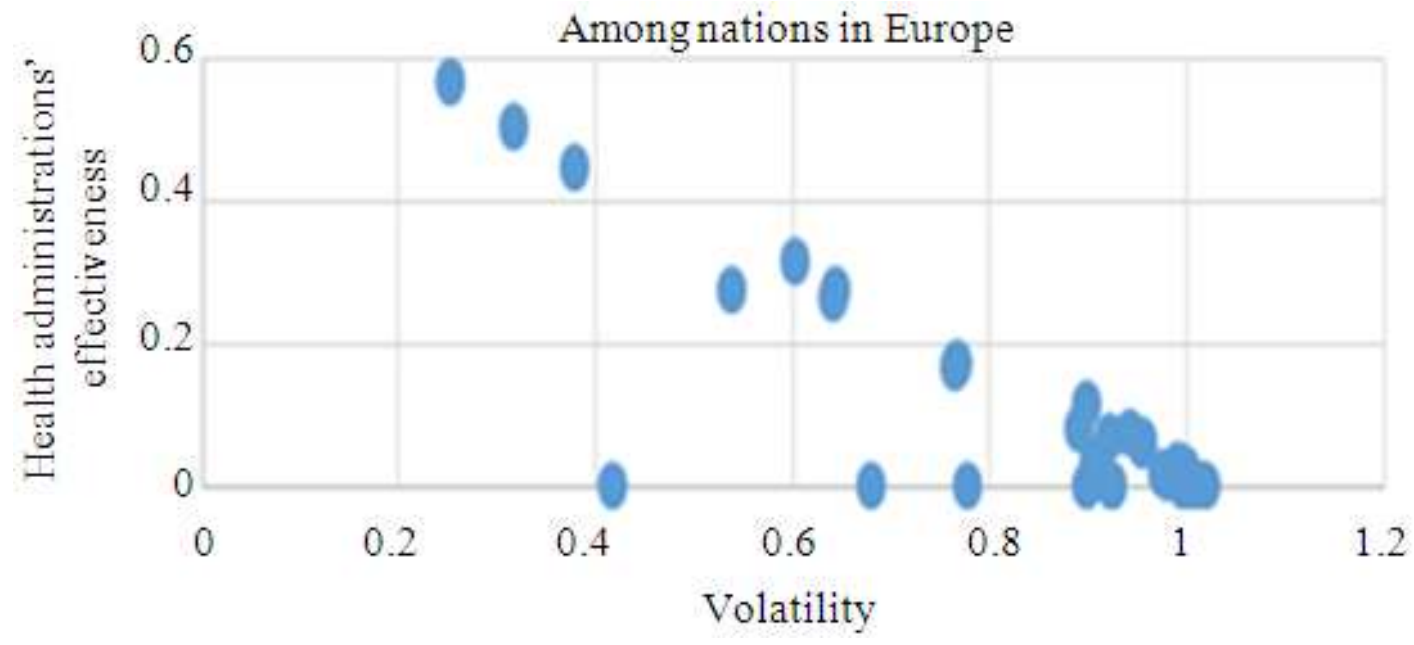

Fig. 12. Health administrators' effectiveness to extinguish H1N1 in Europe

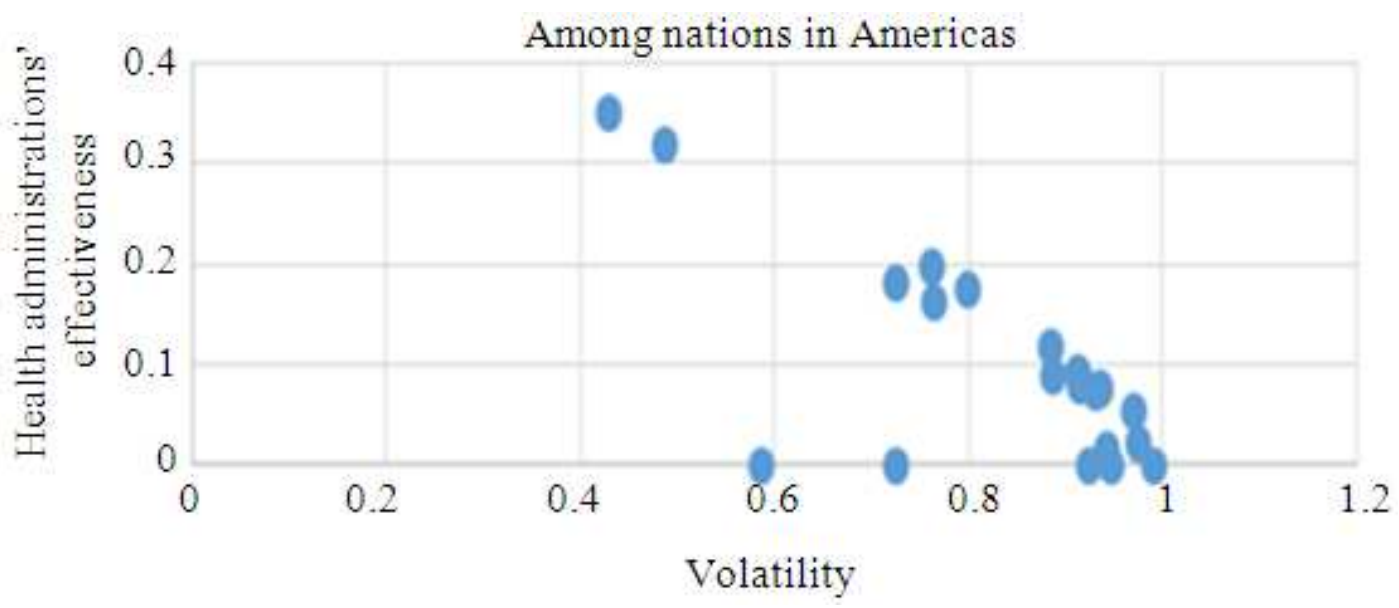

Fig. 13. Health administrators' effectiveness to extinguish H1N1 in Americas 


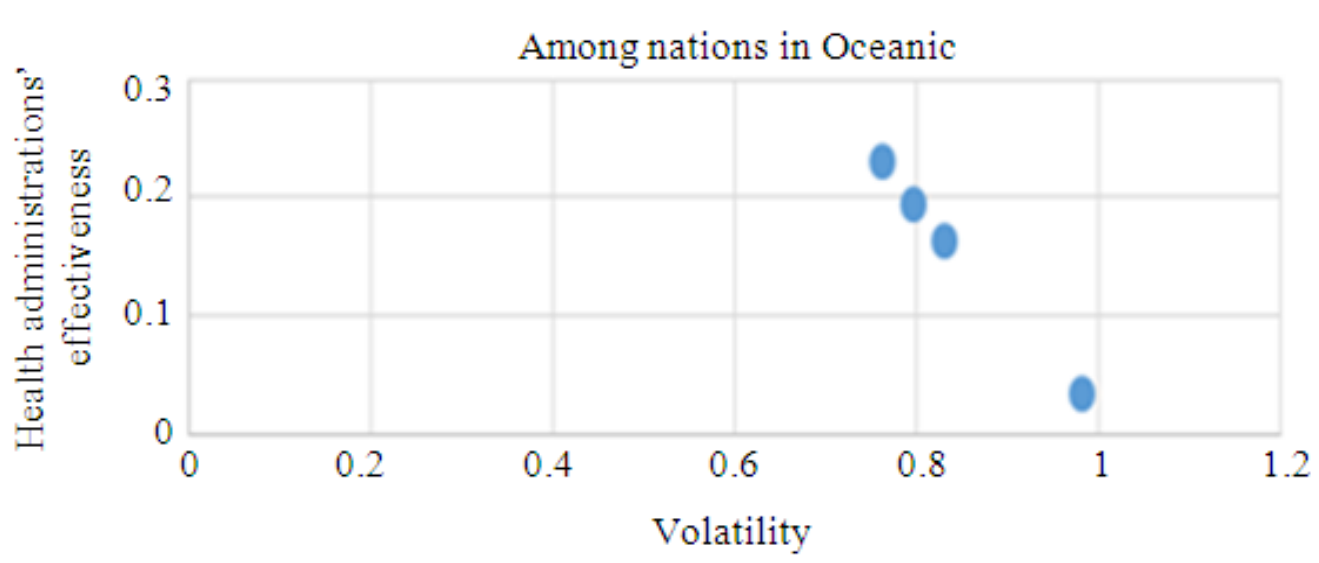

Fig. 14. Health administrators' effectiveness to extinguish H1N1 in Oceanic

Using their parameter estimates: $\hat{\pi}_{0}=\frac{(\# Y=0)}{52}$ and $\hat{\pi}_{1}=\frac{(\# Y=1)}{52}$ and the relationship (9), we obtain an estimate:

$$
\hat{\phi}=\left[1+\hat{r}\left\{\frac{\ln \left[\frac{\hat{\pi}_{1}}{\hat{r}\left(1-\hat{\pi}_{0}^{1 / \hat{r}}\right)}\right]}{\ln \hat{\pi}_{0}}-1\right\}\right]^{-1}
$$

For the actually attained effectiveness, $\phi$ of health administrators' efforts to extinguish the pandemic H1N1. The estimates are displayed in the Table 1 through Table 5 for the five continents. The effectiveness, $\hat{\phi}$ of health administrators' efforts to extinguish pandemic $\mathrm{H} 1 \mathrm{~N} 1$ lessens as the volatility (which is quantified by the variance, $s_{y}^{2}$ ) increases, according to the Fig. 10 through Fig. 14.

\section{Comments and Conclusion}

The estimated chance (see $\hat{\pi}_{0}$ in Table 6) for no H1N1 incidence ranges only between 35 and $42 \%$, not greater than $50 \%$ or higher amount. On the contrary, the estimated chance (see $\hat{\pi}_{1}$ in Table 6 ) for one H1N1 is negligible, meaning that the chance for multiple (that is, two or more) H1N1 incidences are higher than $52 \%$. No wonder the WHO was worried about the pandemic nature of $\mathrm{H} 1 \mathrm{~N} 1$ in all continents.

In the interpretations of section 3, we noticed that the nations within a continent exhibited a varying level of the effectiveness, $\phi$ of health administrators' efforts to extinguish the pandemic H1N1. Obviously, a reason ought to be the existence of heterogeneous environmental factors and people's hygienic habits. It is worth to compare the continents. See Table 6 and Fig. 15 for a summary of the heterogeneity level, $\hat{r}$ and the attained effectiveness, $\hat{\phi}$ of health administrators' efforts to extinguish the pandemic H1N1 in five continents: Africa, Asia, Europe, Americas and Oceanic.

Clearly, the least (based on $\hat{r}$ ) heterogeneous continent is Americas (which are North and South American nations) and the most heterogeneous continent is Asia. The Africa, Europe and Oceanic continents are in between the Americas and Asia in an order. It does not appear that the heterogeneity among the nations in a continent is a factor to the less attained effectiveness, $\hat{\phi}$ of health administrators' efforts to extinguish the pandemic H1N1. The least heterogeneous continent Americas exhibit the lowest effectiveness, $\hat{\phi}$ of health administrators' efforts to extinguish the pandemic H1N1, while the African continent exhibits the highest effectiveness, $\hat{\phi}$ of health administrators' efforts to extinguish the pandemic H1N1.

The most heterogeneous Asian continent exhibits the second low (next to the American continent) effectiveness, $\hat{\phi}$ of health administrator's efforts to extinguish the pandemic H1N1. The other continents: Europe and Oceanic exhibit a reasonable amount of effectiveness, $\hat{\phi}$ of health administrator's efforts to extinguish the pandemic H1N1.

These findings are surprising and are possible because of the versatile and suitable model IRRIBD (6) and the expression (11a) due to the curvature concept. The available information connected to the 2009 H1N1 incidences are limited in the web page. More data on other related predictor variables ought to have been observed and entered in the database so that advanced regression methodology could be built by future researchers to strategize ways and means to improve the effectiveness, $\hat{\phi}$ of health administrators' efforts to extinguish the pandemic H1N1. 


\section{Comparing continenets}

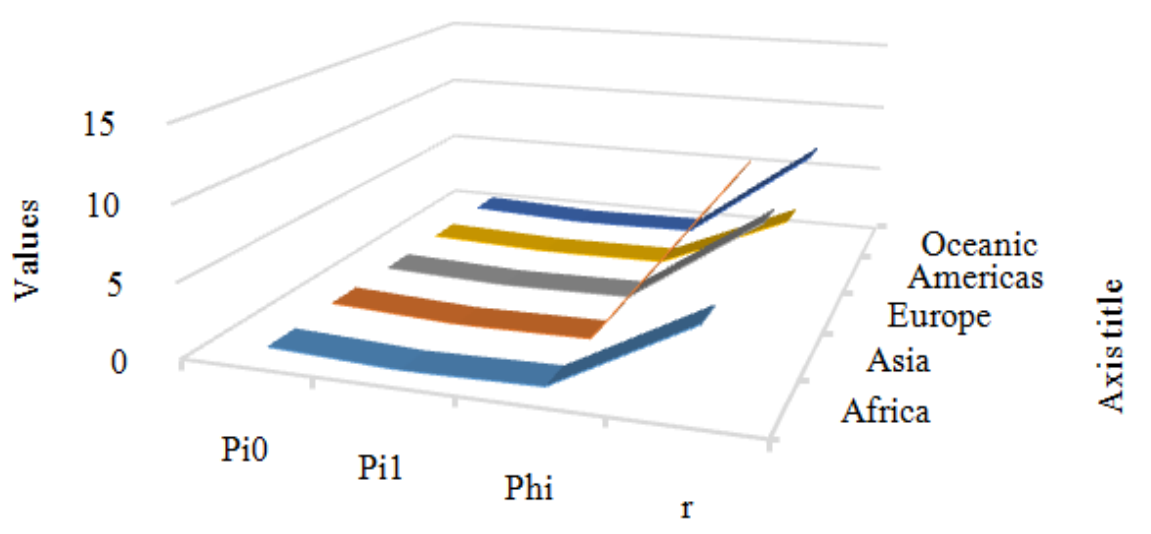

No, one H1N1, effectiveness, heterogenity

$\square$ Africa $\square$ Asia $\square$ Europe $\square$ Americas $\square$ Oceanic

Fig. 15. Contents compared

Table 6. Comparison of $\hat{\pi}_{0}, \hat{\pi}_{1}, \hat{\phi}$ and $\hat{r}$ among the continents

\begin{tabular}{lllll}
\hline Continent & $\begin{array}{l}\text { Proportion of no } \\
\text { incidence, } \hat{\pi}_{0}\end{array}$ & $\begin{array}{l}\text { Proportion of one } \\
\text { incidence, } \hat{\pi}_{1}\end{array}$ & $\begin{array}{l}\text { Effectiveness, } \\
\hat{\phi} \text { to stop H1N1 }\end{array}$ & $\begin{array}{c}\text { Heterogeneity, } \\
\hat{r} \text { among nations }\end{array}$ \\
\hline Africa & 0.42 & 0.024 & 0.204 & 5.168 \\
Asia & 0.46 & 0.028 & 0.138 & 11.83 \\
Europe & 0.35 & 0.025 & 0.165 & 6.396 \\
Americas & 0.36 & 0.031 & 0.127 & 4.093 \\
Oceanic & 0.40 & 0.027 & 0.159 & 6.872 \\
\hline
\end{tabular}

The chance for the effectiveness, $\hat{\phi}$ of the healthcare administrator's efforts to stop H1N1 diminishes when the group becomes more heterogeneous. Hence, the heterogeneity imposes a limitation of the model.

\section{Acknowledgement}

The author appreciates and thanks the Texas State University for offering a sabbatical leave to perform this research work during the spring semester, 2015.

\section{Ethics}

The author confirms that the contents of this article are his own ideas and opinions with with no involment of ethical issues.

\section{References}

Boswell, M.E., J.K. Ord and G.P. Patil, 1990. Chance mechanisms underlying univariate distributions. International Cooperative Publishing House, Butonville.
Cloud, J., 2000. Crossing the Olentangy River: The figure of the earth and the military-industrialacademic-complex, 1947-1972. Studies in History Philosophy Science Part B: Studies History Philosophy Modern Physics, 31: 371-404. DOI: 10.1016/S1355-2198(00)00017-4

Evans, M., N. Hastings and B. Peacock, 2000. Statistical Distributions. 3rd Edn., Wiley, New York, ISBN-10: 0471371246, pp: 248.

Jain, S., L. Kamimoto, A.M. Bramley, A.M. Schmitz and S.R. Benoit et al., 2009. Hospitalized patients with 2009 H1N1 influenza in the United States, AprilJune 2009. New England J. Med., 361: 1935-1944. DOI: 10.1056/NEJMoa0906695

James, C., 1996. Exploring Curvature. 1st Edn., Springer, Braunschweig, ISBN-10: 3528064757, pp: 291.

Saito, S., H. Minakami, A. Nakai, N. Unno and T. Kubo et al., 2013. Outcomes of infants exposed to oseltamivir or zanamivir in utero during pandemic (H1N1) 2009. Am. J. Obstetrics Gynecol., 209: 130 130.e1-130.e9.

DOI: $10.1016 /$ j.ajog. 2013.04 .007 
Smith, G.J., D. Vijaykrishna, J. Bahl, S.J. Lycett and M. Worobey et al., 2009. Origins and evolutionary genomics of the 2009 swine-origin H1N1 influenza a epidemic. Nature, 459: 1122-1125.

DOI: 10.1038 /nature 08182

Sokolov, D.D., 2001. Curvature. In: Encyclopaedia of Mathematics, Hazewinkel, M. (Ed.), Springer Netherlands, ISBN-10: 978-1-55608-010-4.
Vijaykrishna, D., L.L. Poon, H.C. Zhu, S.K. Ma and O.T. Li et al., 2010. Reassortment of pandemic H1N1/2009 influenza a virus in swine. Science, 328: 1529-1529. DOI: 10.1126/science.1189132 